\title{
Knowledge of and barriers to palliative care perceived by healthcare providers before and after promotion of the Patient Autonomy Act: A cross- sectional study
}

\author{
I-Hui Chen \\ National Taipei University \\ Shu-Fen Kuo \\ Taipei Medical University \\ Yen-Kuang Lin \\ Taipei Medical University \\ Tsai-Wei Huang ( $\nabla$ tsaiwei@tmu.edu.tw ) \\ Taipei Medical University https://orcid.org/0000-0002-6722-1153
}

\section{Research article}

Keywords: palliative care, healthcare provider, knowledge, barrier, Patient Autonomy Act

Posted Date: March 30th, 2020

DOI: https://doi.org/10.21203/rs.3.rs-19867/v1

License: (c) (i) This work is licensed under a Creative Commons Attribution 4.0 International License. Read Full License

Version of Record: A version of this preprint was published at International Journal of Environmental Research and Public Health on March 24th, 2022. See the published version at https://doi.org/10.3390/ijerph19073884. 


\section{Abstract}

Background: During the period of 2016 2018, many efforts were put into promoting the Patient Autonomy Act (PAA) in Taiwan, such as nationally sponsoring advertisements, promoting campaigns, and conducting in-service training programs for healthcare providers. However, no study has examined the impacts of promoting the PAA on healthcare providers. This study was designed to investigate healthcare providers' knowledge of palliative care and perceptions of palliative care barriers before and after promoting the PAA.

Methods: A cross-sectional design was conducted in 2013 and 2018 respectively that used a selfreporting questionnaire to examine healthcare providers' knowledge of palliative care and perceived barriers to providing palliative care. One hospital recruited 277 healthcare providers in 2013 and 222 healthcare providers in 2018 in another hospital. Statistical analyses involved descriptive statistics for demographic characters. Multivariate linear regression analyses were used to identify predictors of knowledge of and perceived barriers to palliative care. A principal component analysis was to identify the most appropriate factorial structure for the contents of knowledge and perceived barriers to palliative care.

Results: Three factors related to knowledge of palliative care were identified in both 2013 and 2018 data: 'policy, regulation, and promotion', 'philosophy and treatments', and 'myths and misunderstandings'. Study findings in the two periods were similar. As for barriers to providing palliative care, three factors were identified in 2013 of 'quality palliative care', 'palliative care difficulties' and 'messaging and communication', and in 2018 of 'messaging and information', 'knowledge and attitudes' and 'quality palliative care' were identified. Study findings differed between the two periods.

Conclusion: After implementation of the PAA, perceived barriers changed. Policies can better reinforce mitigating strategies-including opportunities for education, shared decision-making, and changes in institutions and care systems. Also, assessing barriers creates important opportunities for further research to address the most critical aspects to improving end-of-life care for patients and their families.

\section{Background}

Demographic projections indicate that by 2026, one in five Taiwanese will be at least 65 years of age [1], suggesting that increasing numbers of people will be living with terminal conditions and can benefit from palliative care since one of the ultimate goals of palliative care is to achieve a good death [2]. Many western countries have laws about decision-making at the end of life, such as the Patient SelfDetermination Act in the US [3] and the Mental Capacity Act in the UK [4]. Taiwan is among the group of countries where hospice-palliative care services are at a stage of advanced integration into mainstream service provision based on criteria set by Lynch, Connor, and Clark [5].

In 2000, Taiwan became the first country in Asia to enact legislation, the Hospice-Palliative Care Act, related to the controversial topic of natural death. It was enacted for the purpose of respecting medical 
wishes of cancer patients at the terminal stage and safeguarding their rights [6-9]. In 2016, the Patient Autonomy Act (PAA) was passed, and it was enacted in January 2019. The PAA is similar to the Patient Self-Determination Act. The PAA expands upon the existing Hospice-Palliative Care Act and covers a wider range of conditions. The PAA allows all patients to establish an advance decision to decide what kinds of life-sustaining treatment and artificial nutrition and hydration they would refuse in the future, when they are experiencing one of the five following clinical conditions: a terminal illness, an irreversible coma, a permanent vegetative state, severe dementia, and other disease conditions announced by the central competent authority [10]. Additionally, what sets the PAA apart from the Hospice-Palliative Care Act is that it ensures that a patient has the right to be informed regarding their treatment options and decisions regarding that treatment. Based on the PAA, palliative consultations are required to be given to patients before they sign the documents regarding life-sustaining treatments. Through advanced care planning (ACP), patients may sign advance directions (ADs). The ADs shall be made by a person $\geq$ 20 years old and has the legal capacity without being subject to an order of commencement of guardianship [10]. The PAA recommends that if physicians or medical organizations do not comply with a patient's advanced wishes, the patient can be transferred to another hospital. Taiwan is the first country in Asia to pass legislation of this kind to protect and respect patient rights to a good death [11].

The PAA must have impacts on healthcare providers (HPs). Physicians normally do not explain to cancer patients or those whose lives are in danger what condition they are in; instead, they explain and discuss this with the patient's family members $[12,13]$. Also, HPs' conventional obligation was to save a person's life instead of assisting with their death. Having respect for a patient's autonomous right to choose a good death, the PAA mandates that HPs assist a patient's death according to his/her own will. Accordingly, HPs are supposed to be completely adjusted to this condition.

HPs' perceptions about palliative care will influence their execution of the PAA. HPs play major roles in influencing patients' and family's awareness of palliative care [2]. Barriers to providing optimal palliative care have been identified in the existing literature, including an uncertain prognosis, family preferences for more life-sustaining treatment, insufficient knowledge of palliative care [14, 15], and a lack of training and expertise $[14,16]$. In view of this, during the period of $2016 \sim 2018$, many efforts were made to promote the PAA, such as nationally producing many advertisements, and conducting campaigns and inservice training programs for HPs [17]. However, no study has evaluated the impacts on HPs of this effort to promote the PAA. This study was designed to measure HPs' knowledge of palliative care and perceptions of palliative care barriers from the viewpoints of HPs caring for patients. This study investigated two research questions, namely 1) What demographic characteristics influenced HPs' knowledge of palliative care and perceptions of barriers to providing palliative care before and after promoting the PAA?; and 2) What aspects of HPs' knowledge of palliative care and barriers that limited their provision of palliative care changed between before and after promoting the PAA?

\section{Methods}


This study complied with all ethical guidelines for human experimentation stated in the Helsinki Declaration.

This study had a cross-sectional design using a self-reported anonymous questionnaire to examine HPs' (physicians' and nurses') knowledge of palliative care and barriers they encountered to providing palliative care. Surveys were conducted in 2013 (2013 survey) and 2018 (2018 survey). We used the 2018 survey year as a proxy to examine the effects of promoting the PAA. The institutional review board approved the project proposal prior to the initiation of 2013 study [HP 110002] and another study in 2018 [1-106-05-163].

\section{Participants}

Participants were recruited from two regional hospitals located in central and northern Taiwan. For a medium effect size $(d=0.3)$, a power of 0.8 and a significance level of 0.05 , a minimum of 220 participants is required. Inclusion criteria were: (1) aged $\geq 20$ years; (2) working as a physician or nurse; (3) with a license (physician, registered nurse, or licensed practical nurse license); (4) working in the current hospital $\geq 6$ months; (5) able to read Chinese; and (6) willing to participate in this study. Exclusion criteria were students in their internship and HPs who took their leave. In total, convenience samples of 277 HPs (62 physicians and 215 nurses) from the hospital in central Taiwan in 2013 and 222 HPs (53 physicians and 169 nurses) from the hospital in northern Taiwan in 2018 were recruited.

\section{Instruments}

Survey questions were organized into three sections: knowledge of palliative care, perceived barriers to palliative care, and demographics. The scales of knowledge of palliative care and perceived barriers to palliative care were developed based on an extensive review of the literature and the authors' own clinical experience. Knowledge of palliative care scale is composed of 30 items, promotion, myths and misunderstandings, relevance to medical philosophy and treatments in palliative care, informed consent and ADs, and policies and regulations. Four items were reverse items. Perceived barriers to palliative care scale is composed of 32 items, patient and family attitudes, messaging and communication, HPs' attitudes, HPs' ability and training, patient and family knowledge, HPs' knowledge, and relevance to policy resources and economics. Both scales use a 5 -point Likert scale ( $1=$ totally disagree; $5=$ totally agree). A higher scores indicates a greater knowledge of palliative care or the presence of more barriers to palliative care. The two scales had good validity and reliability [18]. Demographics included age, gender, job tenure, marital status, educational level, and working unit.

\section{Statistical analysis}

Demographics were reported as the mean, standard deviation (SD), and proportion. Multivariate linear regression analyses were used to identify predictors of knowledge of and perceived barriers to palliative care. A principal component analysis was employed allowing us to identify the most appropriate factorial structure for contents of knowledge of palliative care in 2013 and 2018, as well as for contents of 
perceived barriers to palliative care in 2013 and 2018. p values were two-sided and considered significant at $<0.05$. Statistical analyses were performed with IBM SPSS 22.0 [19].

\section{Results}

\section{Characteristics of participants}

As shown in Table 1, in the 2013 survey, the average age of participants was 33.2 (SD $=8.1$ ) years. The majority were female (79.4\%), had working experience of over a decade (36.1\%), were unmarried (50.2\%), had a bachelor degree (62.8\%), and worked in the medical or surgical ward (58.5\%). Mean scores for knowledge of palliative care and perceived barriers to palliative care were 112 (SD = 15.0) and 105.9 (SD $=17.9)$, respectively. In the 2018 survey, the average age of participants was $32.1(S D=8.5)$ years. The majority were female (78.8\%), had working experience of over a decade (33.3\%), were unmarried (50.0\%), had a bachelor's degree (61.7\%), and worked in the medical or surgical ward (49.5\%). Mean scores for knowledge of palliative care and perceived barriers to palliative care were $115(\mathrm{SD}=14.6)$ and $99.6(\mathrm{SD}=$ 15.8), respectively. All participants approached agreed to participate in the study, but two surveys were incomplete in 2018. 
Table 1

Characteristics of participants.

\begin{tabular}{|c|c|c|}
\hline & $\begin{array}{l}2013 \\
N=277\end{array}$ & $\begin{array}{l}2018 \\
N=222\end{array}$ \\
\hline Variable & Mean (SD)/n (\%) & Mean (SD)/n (\%) \\
\hline Age (years) & $33.2(8.1)$ & $32.1(8.5)$ \\
\hline \multicolumn{3}{|l|}{ Gender } \\
\hline Female & $220(79.4)$ & $175(78.8)$ \\
\hline \multicolumn{3}{|l|}{ Job tenure (years) } \\
\hline$<1$ & $1(0.4)$ & $17(7.7)$ \\
\hline $1 \sim 2$ & $45(16.2)$ & $42(18.9)$ \\
\hline $3 \sim 4$ & $48(17.3)$ & $31(14.0)$ \\
\hline $5 \sim 6$ & $29(10.5)$ & $28(12.6)$ \\
\hline $7 \sim 10$ & $54(19.5)$ & $30(13.5)$ \\
\hline$>11$ & $100(36.1)$ & $74(33.3)$ \\
\hline \multicolumn{3}{|l|}{ Marital status } \\
\hline Married & $135(48.7)$ & $109(49.1)$ \\
\hline Unmarried & $140(50.2)$ & $111(50.0)$ \\
\hline Divorced & $2(0.7)$ & $2(0.9)$ \\
\hline \multicolumn{3}{|l|}{ Educational level } \\
\hline Junior college & $85(30.6)$ & $74(33.3)$ \\
\hline Bachelor's degree & $174(62.8)$ & $137(61.7)$ \\
\hline Graduate school & $18(6.5)$ & $11(5.0)$ \\
\hline \multicolumn{3}{|l|}{ Working unit } \\
\hline Medical/surgical ward & $162(58.5)$ & $110(49.5)$ \\
\hline Emergency/intensive care unit & $71(25.6)$ & 85 (38.3) \\
\hline Other & $44(15.9)$ & $27(12.2)$ \\
\hline Knowledge of palliative care & $112(15.0)$ & $115(14.6)$ \\
\hline
\end{tabular}

SD: standard deviation. 


\begin{tabular}{|lll|}
\hline & $\begin{array}{l}2013 \\
\mathbf{N}=277\end{array}$ & $\begin{array}{l}2018 \\
\mathbf{N}=222\end{array}$ \\
\hline Perceived barriers to palliative care & $105.9(17.9)$ & $99.6(15.8)$ \\
\hline SD: standard deviation. & & \\
\hline
\end{tabular}

\section{Predictors of knowledge of palliative care and perceived barriers to palliative care}

In Table 2, no variables were significantly related to knowledge of palliative care in 2013. Having a junior college degree $(B=-0.309, p=0.03)$ and a bachelor's degree $(B=-0.298, p=0.03)$ were significantly related to knowledge of palliative care in 2018.

Table 2

Predictive variables of knowledge of palliative care.

\begin{tabular}{|c|c|c|c|c|c|c|c|c|}
\hline & 2013 & & & & 2018 & & & \\
\hline Variable & B & SE & $\mathrm{t}$ & $\mathrm{p}$ & B & SE & $\mathrm{t}$ & $\mathrm{p}$ \\
\hline Age & -0.001 & 0.006 & -0.17 & 0.87 & -0.007 & 0.006 & -1.13 & 0.26 \\
\hline Job tenure & 0.006 & 0.028 & 0.20 & 0.84 & 0.002 & 0.029 & 0.08 & 0.93 \\
\hline \multicolumn{9}{|c|}{ Educational level (graduate school as the reference) } \\
\hline Junior college & 0.024 & 0.128 & 0.19 & 0.85 & -0.309 & 0.142 & -2.18 & 0.03 \\
\hline Bachelor's & 0.015 & 0.115 & 0.13 & 0.90 & -0.298 & 0.134 & -2.23 & 0.03 \\
\hline \multicolumn{9}{|c|}{ Marital status (divorced as the reference) } \\
\hline Unmarried & 0.353 & 0.308 & 1.14 & 0.25 & -0.506 & 0.302 & -1.68 & 0.09 \\
\hline Married & 0.415 & 0.313 & 1.33 & 0.19 & -0.489 & 0.299 & -1.64 & 0.10 \\
\hline \multicolumn{9}{|l|}{ Gender (male as the reference) } \\
\hline Female & -0.145 & 0.086 & -1.68 & 0.09 & 0.155 & 0.080 & 1.93 & 0.05 \\
\hline \multicolumn{9}{|c|}{ Working unit (other as the reference) } \\
\hline $\begin{array}{l}\text { Medical/ } \\
\text { surgical ward }\end{array}$ & 0.057 & 0.074 & 0.76 & 0.45 & 0.038 & 0.091 & 0.42 & 0.68 \\
\hline Emergency/intensive care unit & 0.158 & 0.83 & 1.89 & 0.06 & -0.0004 & 0.093 & 0 & 1.00 \\
\hline
\end{tabular}

Age $(B=-0.019, p=0.03)$ and job tenure $(B=0.119, p=0.001)$ were significantly related to perceived barriers to palliative care in 2013. Having a junior college degree $(B=-0.562, p=0.0008)$ and a bachelor's 
degree $(B=-0.376, p=0.02)$ predicted perceived barriers to palliative care in 2018 (see Table 3 ).

Table 3

Predictive variables of perceived barriers to palliative care.

\begin{tabular}{|c|c|c|c|c|c|c|c|c|}
\hline & 2013 & & & & 2018 & & & \\
\hline Variable & B & SE & $\mathrm{t}$ & $\mathrm{p}$ & $\mathrm{B}$ & SE & $\mathrm{t}$ & $\mathrm{p}$ \\
\hline Age & -0.019 & 0.009 & -2.21 & 0.03 & 0.001 & 0.008 & 0.14 & 0.89 \\
\hline Job tenure & 0.119 & 0.036 & 3.29 & 0.001 & 0.038 & 0.034 & 1.12 & 0.26 \\
\hline \multicolumn{9}{|c|}{ Educational level (graduate school as the reference) } \\
\hline Junior college & -0.155 & 0.164 & -0.94 & 0.35 & -0.562 & 0.166 & -3.39 & 0.0008 \\
\hline Bachelor's & -0.076 & 0.147 & -0.52 & 0.61 & -0.376 & 0.157 & -2.4 & 0.02 \\
\hline \multicolumn{9}{|c|}{ Marital status (divorced as the reference) } \\
\hline Unmarried & 0.398 & 0.395 & 1.01 & 0.32 & -0.308 & 0.353 & -0.87 & 0.38 \\
\hline Married & 0.505 & 0.401 & 1.26 & 0.21 & -0.413 & 0.349 & -1.18 & 0.23 \\
\hline \multicolumn{9}{|c|}{ Gender (male as the reference) } \\
\hline Female & 0.051 & 0.157 & 0.32 & 0.74 & 0.108 & 0.164 & 0.66 & 0.51 \\
\hline \multicolumn{9}{|c|}{ Working unit (others as the reference) } \\
\hline Medical/ surgical ward & 0.031 & 0.095 & 0.33 & 0.74 & -0.016 & 0.107 & -0.15 & 0.88 \\
\hline $\begin{array}{l}\text { Emergency/ intensive care } \\
\text { unit }\end{array}$ & 0.121 & 0.107 & 1.13 & 0.26 & 0.025 & 0.109 & 0.23 & 0.82 \\
\hline
\end{tabular}

SE: standard error.

\section{Factors affecting changes in knowledge of palliative care and perceived barriers to palliative care}

A three-factor model gave an adequate description of the data of knowledge of palliative care. In 2013 data (see Fig. 1), most items with salient loadings on factor 1 contained a variety of non-overlapping policies and regulations, and promotion. This factor was labeled 'policies, regulations, and promotion'. Factor 2 contained a variety of items describing different aspects of medical philosophy and palliative care treatments. This factor was labeled 'philosophy and treatments'. Factor 3 contained items describing myths and misunderstandings, informed consent, and ADs. This factor was labeled 'myths and misunderstandings'. In 2018 data (see Fig. 1), the pattern of factor 1 was the same as factor 1 in 2013. This factor was labeled 'policies, regulations, and promotion'. Factor 2 was still labeled 'philosophy and treatments'. This factor contained not only items of medical philosophy and treatments in palliative care, 
but also items describing informed consent and ADs. Factor 3 was labeled 'myths and misunderstandings'. This factor only contained items describing myths and misunderstandings.

A three-factor model also provided an adequate description of the data of perceived barriers to palliative care. In the 2013 data (see Fig. 2), most items with salient loadings on factor 1 contained a variety of policy resources and economics, professional ability and training, messaging and communication, professional knowledge, professional attitudes, patient and family knowledge, and patient and family attitudes. This factor was labeled 'quality palliative care'. Factor 2 contained items describing how HPs, patients, and families reflected difficulties in implementing palliative care. The factor was labeled 'palliative care difficulties'. Factor 3 mainly contained items describing issues regarding how patients and families received messages and information from professionals, and communication of HPs with patients and families. Hence, factor 3 was labeled 'messaging and communication'. In the 2018 data (see Fig. 2), factor 1 contained items describing information of policy resources and economics, information from HPs, and information about decision making. Factor 1 was labeled 'messaging and information'. Factor 2 mainly contained items describing knowledge and attitudes of HPs and patients and family members; hence, this factor was labeled 'knowledge and attitudes'. Factor 3 was labeled 'quality palliative care'. However, the patterns differed from factor 1 in 2013 since this factor mainly contained items describing labor resources and capital resources.

\section{Discussion}

Elevating the knowledge of palliative care in HPs and evaluating how these perceived barriers have changed or persisted over time can help better develop mitigating strategies-including opportunities for education, staffing, and changes in institutions and care systems. Assessing these barriers creates opportunities for further research to address the most critical aspects in improving end-of-life care for patients and their families. Evidence demonstrated the benefits of palliative care for patients, and understanding knowledge and perceived barriers to palliative care in hospitals is important to expanding access and acceptance of this specialized care for critically ill patients and their families [20]. HPs act as mediators between patients and their families, and between patients and their healthcare teams. A paper found that $79 \%$ of participants would use hospice if it were recommended by their physician [21]. Additionally, nurses help families be more aware of patients' views and concerns, and view the situation more realistically $[22,23]$. Interestingly, we found that the higher the level of education, the higher the scores of perceived barriers in HPs in 2018. HPs with a graduate degree perceived greater barriers than did providers with a university or junior college degree. Because most providers with graduate degree were head or specialist nurses and they have been consciously responsible for promoting the PAA, they perceived that barriers were higher. It is recommended that PAA- and ACP-related training be included in annual mandatory continuing education for HPs [20,24]. Particularly, HPs with managerial roles must undergo educational training of coordination or multidisciplinary consultations [24, 25].

Compared to 2013, total scores in 2018 of perceived knowledge of palliative care of HPs had significantly increased $(p=0.028)$. Taking the factors of 'myths and misunderstandings' as an example, in the 2013 
survey, HPs' informed consent and advanced decision-making instructions for patients and their families were classified in 'myths and misunderstandings'. Physicians themselves are still troubled by the need to "describe the terminal illness" to the patient. Physicians think that "the doctor needs to save the patient's life" instead of allowing the patient to face death. In the early stages of an illness, HPs rarely discuss and communicate "about death" with patients and their families. It is difficult for physicians to predict life expectancy and they may lack an understanding of patient eligibility guidelines; it is difficult for HPs to explain the patient's condition and give informed consent [14]. By 2018, informed consent and decisionmaking directives seemed to have been more widely accepted and classified as 'philosophy and treatment' factors. This may indicate that the concept of palliative care is gradually improving among HPs. According to the PAA, patients can sign a medical decision form expressing whether they accept or reject receiving medical treatment beforehand when they still maintain full civil capacity [10]. The PAA addresses informed consent and decision making, and allows patients to decide whether or not to receive medical treatments in the end stage of a disease. Thus, the ACP advocates the importance of communication in shared decision-making for patients who have a critical illness or who are known to be moving towards the end of life. It is defined as a voluntary discussion of a patient with his/her care provider(s) and family, drawing on a person's values, goals, and concerns, and any preferences for particular treatments [26]. The process of discussing, consulting, and documenting the wishes and preferences of future care, where possible, offering patients the opportunity to discuss important personal issues is considered an important improvement in care quality. In this study, the perceived knowledge of HPs also showed that the PAA has had a great effect. This shows that informed consent and decisionmaking have been included in the 'philosophy and treatment' of palliative care. HPs have positive attitudes about ACP after implementation of the PAA.

In 2018, the total score of barriers to palliative care perceived by HPs was significantly lower than that in 2013 ( $p$ < 0.001). Also, the patterns of perceived barriers had changed. In the 2013 survey, HPs faced many difficulties, including a lack of confidence in promoting palliative care, avoidance of talking about death and related issues, etc. Since enactment of the decree, we observed that the proportion of certain HPs who have experienced obstacles has changed. The Ministry of Health and Welfare in Taiwan announced the participation in hospice as a basic human right [27]. The government cooperates with the instructions and promotion of the PAA, and HPs must participate in PAA training to qualify for certification. Most hospitals have hospice wards, hospice palliative home care, and shared care, in order to improve utilization of palliative care. This has had a positive impact, and utilization is rising year to year. However, there are still many difficulties which need solutions. After the promotion of the PAA, these difficulties transited into knowledge and attitudes that HPs must possess, but education and training can be used to help HPs cope with these difficulties. As to dimensions of information and communication between the 2013 and 2018 surveys, end-of-life care, misunderstanding palliative care, information on participation in decision-making, and pre-testamentary legal factors still plague HPs, patients, and their families. However, the PAA ensures that patients have the right to know all about their condition, and then they can make a decision before the end of life. Promotion of the PAA has encouraged information sharing and communication among HPs, patients, and families. 
As to changes over the 5 years, HPs have reduced implementation barriers through PAA training. Shared decision-making (SDM) is seen as a key component of patient-centered care and emphasizes the importance of physician-patient relationships in optimizing health outcomes [28]. With progress of the PAA, SDM is an important tool for HPs to discuss the life decision-making process with patients and their families. To help HPs face possible obstacles and facilitate decision-making require staff confidence in end-of-life discussions when working with patients and their families while respecting the influence of filial piety, a central value in traditional Chinese culture [29]. HPs should grasp the chance to carry out these sharing procedures when a decision is required.

\section{Strengths and Limitations}

This is the first study in Asia to compare knowledge and perceived barriers among HPs before and after promotion of the PAA. Three factors of knowledge and perceived barriers identified can help HPs and stakeholders focus on them and develop interventions. Informed consent and decision-making were seen as 'myths and misunderstandings' in 2013, but changed to being a part of 'philosophy and treatment' in 2018. Accordingly, stakeholders may provide educational training in this direction. There are some limitations to this study. The survey was conducted in two local teaching hospitals in central and northern Taiwan. Even though the two hospitals were of comparable size and property, there might still be differences between the two hospitals. The results should be interpreted with caution. Also, although respondents of physicians and nurses represented a wide range of experiences in local hospitals, the surveys did not include other HPs, such as social workers, or psychotherapists. The results might not can be generalized to other HPs. Future research should be conducted on other HPs.

\section{Conclusions}

Our study investigated changes in knowledge and barrier perceptions during 5 years before and after promoting the PAA. HPs need to be aware of improvements in policies and regulations, and assist patients in a timely manner. This study showed that after the PAA policy was promoted, knowledge of HPs increased while the perceived barriers decreased. Although there are still some obstacles, such as soft and hard resources, the government should provide more on-the-job education for HPs on palliative care.

\section{Abbreviations}

PAA, Patient Autonomy Act; HPs, healthcare providers; ACP, advanced care planning; Ads, advance directions.

\section{Declarations}

\section{Ethics approval and consent to participate}


This research was approved by the two institutions, namely the Cheng Ching General Hospital, Taiwan [approved number: HP 110002]; and the Tri-Service General Hospital, Taiwan [approved number: 1-106-05163].

All subjects were informed about the aims of the study and gave written informed consent prior to their participation and the records did not contain information that could identify the participants. This study complied with all ethical guidelines for human experimentation stated in the Helsinki Declaration.

\section{Consent to publish}

Springer Nature remains neutral with regard to jurisdictional claims in published maps and institutional affiliations.

\section{Availability of data and materials}

The data sets used and analyzed during the current study are available from the corresponding author on reasonable request.

\section{Competing interests}

The authors declare that they have no competing interests.

\section{Funding}

No funding was obtained for this study.

\section{Authors' contributions}

IHC interpreted the data and drafted the article; SFK interpreted the data and data entry; YKL statistics and interpreted data; TWH interpreted the data, review study design, writing the result section, and revised the manuscript. All authors have read and approved the final manuscript.

\section{Acknowledgements:}

We are grateful for the company, Wallace Academic Editing, for assisting this article. The authors thank all the participates for their assistance and contribution to this research.

\section{References}

1. Taiwan National Development Council. Population projections of Republic of China (2018 2065) 2018, https://www.ndc.gov.tw/Content_List.aspx?n=84223C65B6F94D72 (accessed 3 September 2019).

2. World Health Organization (WHO). Palliative care 2018, https://www.who.int/news-room/factsheets/detail/palliative-care (accessed 13 August 2019). 
3. Mezey M, Mitty E, Rappaport M, et al. Implementation of the Patient Self-Determination Act (PSDA) in nursing homes in New York City. J Am Geriatr Soc 1997; 45(1):43-49.

4. McDonald A. The impact of the 2005 Mental Capacity Act on social workers' decision making and approaches to the assessment of risk. Br J Soc Work 2010; 40:1229-1246.

5. Lynch T, Connor S and Clark D. Mapping levels of palliative care development: a global update. J Pain Symptom Manage 2013; 45(6):1094 -1106.

6. Yang CL, Chiu TY, Hsiung YF, et al. Which factors have the greatest influence on bereaved families' willingness to execute advance directives in Taiwan? Cancer Nurs 2011; 34(2), 98-106.

7. Tang ST, Chen ML, Huang EW, et al. Hospice utilization in Taiwan by cancer patients who died between 2000 and 2004. J Pain Symptom Manag 2007; 33(4):446-453.

8. Chang HT, Lin MH, Chen $\mathrm{CK}$, et al. Trends of do-not-resuscitate consent and hospice care utilization among non-cancer decedents in a tertiary hospital in Taiwan between 2010 and 2014: a hospitalbased observational study. Med 2016; 95(46):e5394.

9. Shih TC, Chang HT, Lin MH, et al. Trends of do-not-resuscitate orders, hospice care utilization, and late referral to hospice care among cancer decedents in a tertiary hospital in Taiwan between 2008 and 2014: a hospital-based observational study. J Palliat Med 2017; 20(8):838-844.

10. Law \& regulations database of the Republic of China. The Patient Autonomy Act, https://law.moj.gov.tw/LawClass/LawAll.aspx?pcode=L0020189 (accessed 20 April 2019).

11. Ministry of Health and Welfare. Taiwan's dying patient's death quality ranks first in Asia, and continues to strengthen 'palliative care' as one of the 'integrated health care', https://www.mohw.gov.tw/fp-2627-19127-1.html (2016, accessed 20 April 2019).

12. Lin CP, Cheng SY and Chen PJ. Advance care planning for older people with cancer and its implications in Asia: highlighting the mental capacity and relational autonomy. Geriatrics (Basel) 2018; 3(3): E43.

13. Dong $F$, Zheng R, Chen $X$, et al. Caring for dying cancer patients in the Chinese cultural context: a qualitative study from the perspectives of physicians and nurses. Eur J Oncol Nurs 2016; 21:189196.

14. Brickner L, Scannell K, Marquet S, et al. Barriers to hospice care and referrals: survey of physicians' knowledge, attitudes, and perceptions in a health maintenance organization. J Palliat Med 2004; 7(3):411-418.

15. Davies B, Sehring SA, Partridge JC, et al. Barriers to palliative care for children: perceptions of pediatric health care providers. Pediatr 2008; 121(2): 282-288.

16. Kavalieratos D, Mitchell EM, Carey TS, et al. "Not the 'grim reaper service"': an assessment of provider knowledge, attitudes, and perceptions regarding palliative care referral barriers in heart failure. J Am Heart Assoc 2014; 3(1):e000544.

17. Ministry of Health and Welfare. 2018 Annual health education spindle project key work and strategy, https://www.mohw.gov.tw/lp-173-1.html (accessed 20 April 2019). 
18. Jiang ZY. Exploring medical staff awareness and barrier analysis in terminal cancer patients in hospice care. Unpublished master thesis, Taichung: Hungkuang University, 2013.

19. IBM Corporation. IBM SPSS statistics for Windows, version 22.0. Armonk, NY: IBM: Corporation, 2013.

20. Hawley P. Barriers to access to palliative care. Palliat Care 2017; 10:1178224216688887.

21. Spruill AD, Mayer DK and Hamilton JB. Barriers in hospice use among African americans with cancer. J Hosp Palliat Nurs 2013; 15(3):136-144.

22. Black K. Advance directive communication: nurses' and social workers' perceptions of roles. Am J Hosp Palliat Care 2006; 23:175-184.

23. Seymour J, Almack K and Kennedy S. Implementing advance care planning: a qualitative study of community nurses' views and experiences. BMC Palliat Care 2010; 9: 4.

24. Ke LS, Huang $X$, O'Connor $M$, et al. Nurses' views regarding implementing advance care planning for older people: a systematic review and synthesis of qualitative studies. J Clin Nurs 2015; 24:20572073.

25. Tran M, Grant M, Clayton J, et al. Advance care decision making and planning. Aust J Gen Pract 2018; 47(11):753 -757.

26. National Health Service (NHS). Advance care planning: a guide for health and social care staff. London: Department of Health 2008, https://www.nhs.uk/planners/end-of-lifecare/documents/planning-for-your-future-care.pdf

27. Ministry of Health and Welfare. Enjoy hospice as a basic human right 2015, https://www.hpa.gov.tw/Pages/Detail.aspx?nodeid=1128\&pid=1950 (accessed 29 September 2019).

28. Barry MJ and Edgman-Levitan S. Shared decision making-pinnacle of patient-centered care. N Engl J Med 2012; 366(9):780-781.

29. Lin CP, Evans CJ, Koffman J,et al. What influences patients' decisions regarding palliative care in advance care planning discussions? Perspectives from a qualitative study conducted with advanced cancer patients, families and healthcare professionals. Palliat Med 2019; 269216319866641.

\section{Figures}




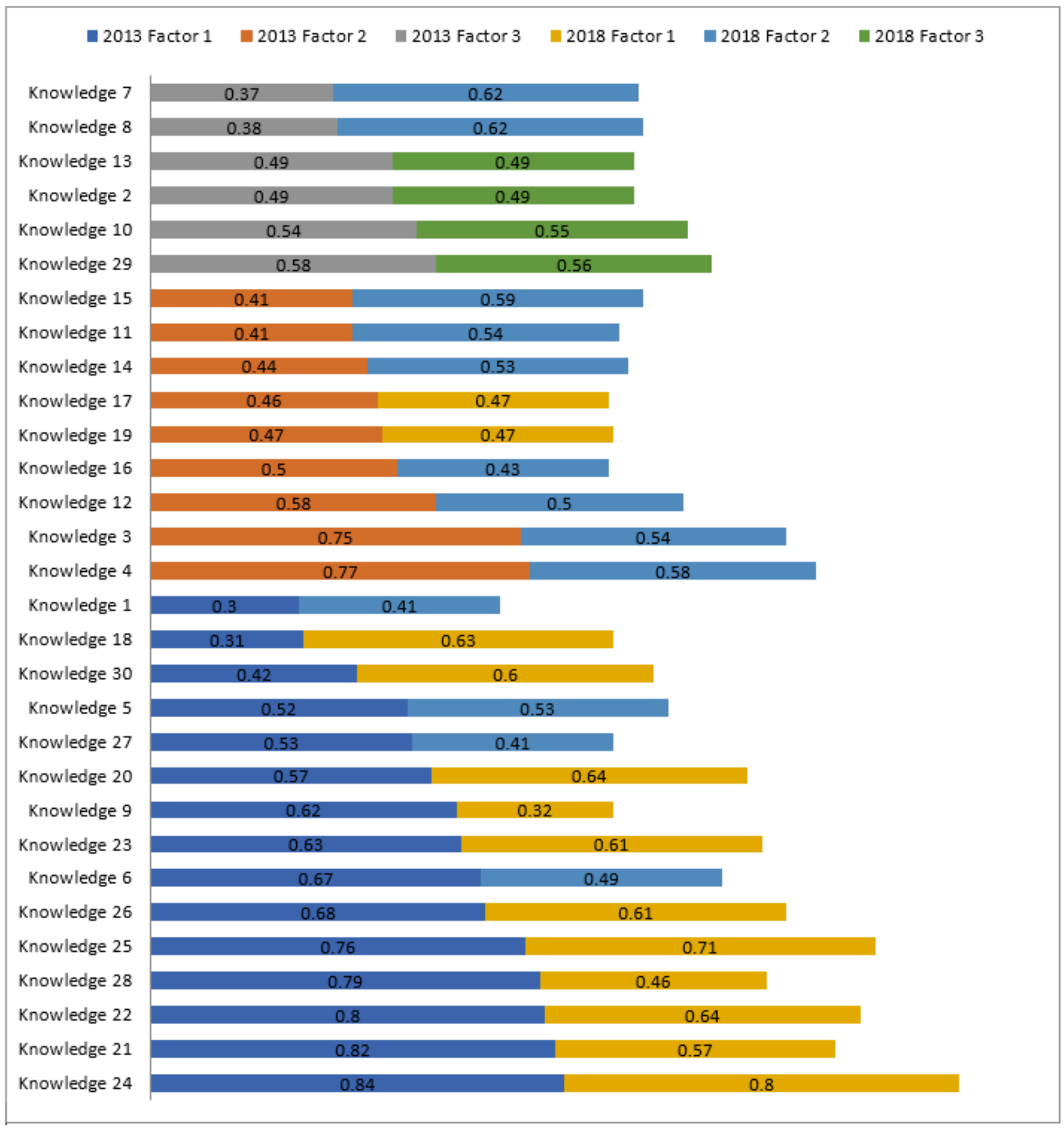

\section{Figure 1}

Factor loadings for items of the scale of knowledge of palliative care in 2013 and 2018 


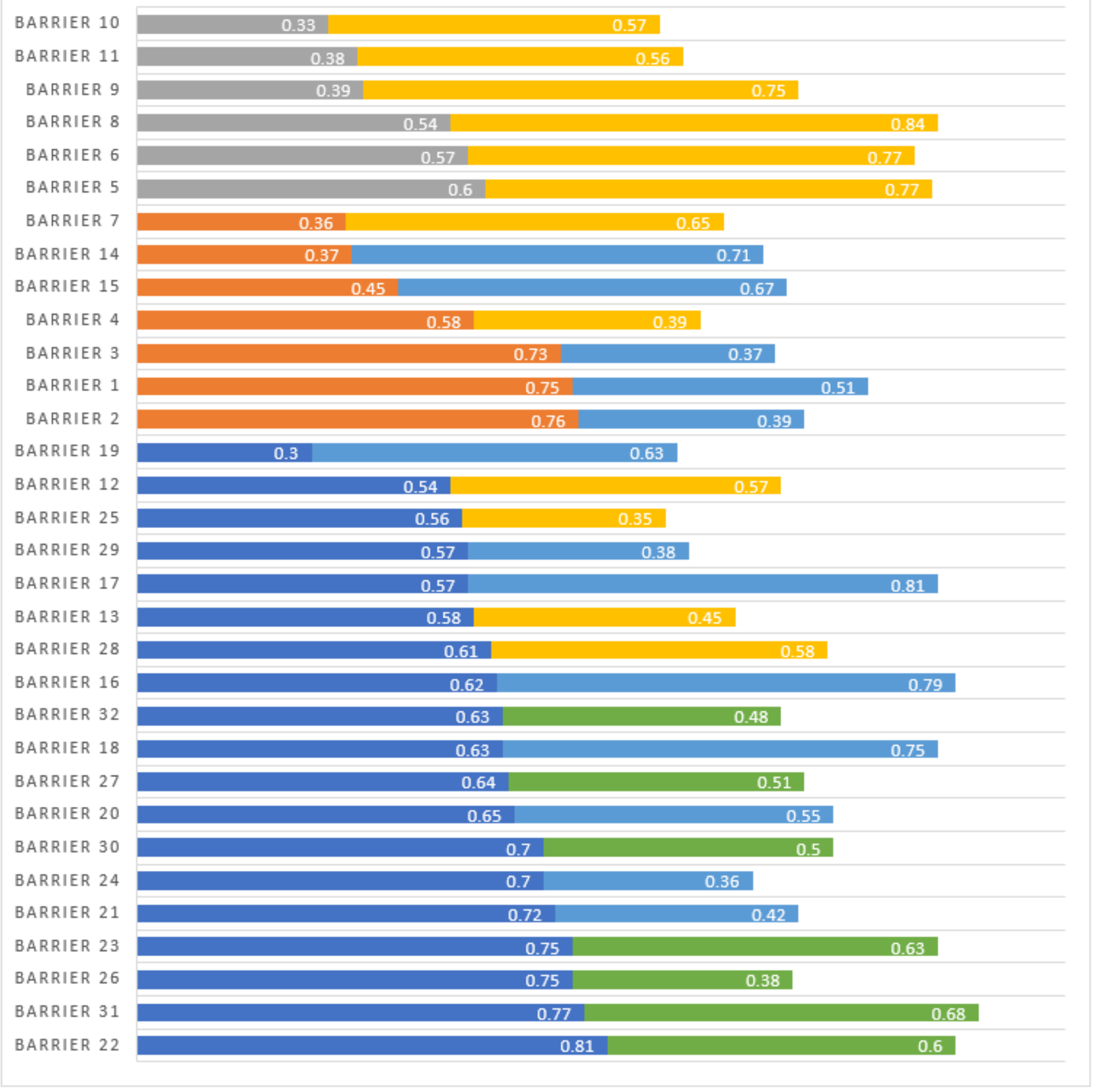

\section{Figure 2}

Factor loadings for items of the scale of perceived barriers to palliative care in 2013 and 2018

\section{Supplementary Files}

This is a list of supplementary files associated with this preprint. Click to download. 
- Supplemental1.docx

- STROBEchecklistcrosssectional.docx 